\title{
PANORAMA DOS ÓRgãos ENVOLVIDOS NO SISTEMA dE SEgURANÇA SANITÁRIA dOS ESTADOS UNIDOS DA AMÉRICA
}

A VIEW OF THE INVOLVED AGENCES WITH THE HEALTH SAFETY SYSTEM

AT THE UNITED STATES OF AMERICA

Rohert M. Spiller, Jr. ${ }^{*_{1}}$

\section{RESUMO}

O sistema de saúde americano visa a unir dois aspectos: a economia de mercado no setor privado e um sistema de saúde que não se restringe aos mais privilegiados. O FDA tem uma estrutura montada para proteção à saúde desenvolvida através da fiscalizaçāo de produtos e da fiscalização de condutas. As ações desenvolvidas são: procedimentos relativos à aprovação de um novo produto; remoção e confisco de produto ilegal; provocação judicial com pedido de medida cautelar; e representação ao Departamento de Justiça para instauração de processo criminal. Muitos casos são resolvidos, ainda, em processo quase judicial, por meio de um Termo de Ajuste de Conduta.

\section{Palavras-chave}

Controle Sanitário, Saúde Pública, Direito Sanitário, Segurança Sanitária.

\section{ABSTRACT}

The American health system aims linking two aspects: the market's economy in private sector and a health system which is not restricted to the most privileged persons. The FDA has a structure to protect health which is developed by several mechanisms, which are: products and behaviors control. Actions such as: proceedings to approve a new product, removal and

$\left({ }^{*}\right)$ Chefe associado do Escritório Jurídico para Garantia e Implementação do Conselho Superior de Food and Drug Administration dos Estados Unidos da América. 
confiscation of illegal product, asking justice to avoid an enterprise transgressing the law and a formal petition asking the Justice Department to start a criminal process against law transgressors, can be done by FDA. Many cases are solved without a complete judgment but by a Consent Decree.

\section{Key words}

Health Law, Health Safety, Public Health, Health Control.

\section{COMPLEXIDADE EM DESENVOLVIMENTO}

Nos Estados Unidos, nós gradualmente desenvolvemos um sistema complexo de proteção à saúde. Nosso complexo sistema é reflexo de nossos anseios em ter tanto uma economia de mercado no setor privado como assegurar que um bom sistema de saúde não fique restrito àqueles que têm mais dinheiro. Eu acredito que o setor de saúde pública, através dos séculos, vem sendo vítima do reconhecimento público de que, mesmo se quiséssemos fornecer bons sistemas de saúde para apenas uma parcela da população, isso não funcionaria: as doenças e as condições que permitem o seu crescimento ultrapassam tanto as barreiras naturais quanto aquelas feitas pelo homem, e espalham-se de uma comunidade à outra, de um estado, de uma nação à outra, ao redor do mundo. Desse modo, obtivemos melhoras nos sistemas de proteção à saúde que possam amparar toda a população, e não apenas aqueles que têm condiçōes financeiras para ter assistência dos melhores médicos, ou daqueles que moram perto dos meIhores hospitais.

Nos Estados Unidos, temos uma longa tradição de "governo minimalista", já que nosso governo foi projetado por pessoas que inicialmente foram unidas por um desejo comum de rejeitar um governo estrangeiro que se apoderasse de nossa colônia. Em nosso entusiasmo ao rejeitar tal controle centralizado e remoto, nossa Constituição e as Leis subordinadas a ela criaram apenas uma estrutura nacional de proteção à saúde. Uma vez que somos descendentes de pessoas que foram oprimidas por governos ostensivos, criamos leis de proteção à saúde que vieram apenas em resposta a eventos dramáticos, tais como drogas que envenenam, ou drogas com terriveis efeitos colaterais retardados, e patogêneses relacionadas a alimentos, desse modo causando doenças em grande número de pessoas.

A lei que minha agência (o FDA) administra é uma delas ou seja, primeiramente esboçada em resposta a precárias condições sanitárias na indústria de processamento alimentício, e substancialmente fortalecida (quanto à regulação das drogas) quando um fabricante de medicamentos específico matava mais de cem pacientes com uma nova droga inadequadamente formulada. Tais eventos mobilizavam o apoio público, forneciam argumen- 
tos para que figuras politicas atacassem o problema, e nos motivava a superar nossa relutância em acrescentar mais leis, regulamentos e sistema de governo à já restrita estrutura vigente.

Então, as estruturas organizacionais e legais que nos restaram não são o somatório de um grande desejo ou de um grande plano cuidadosamente elaborado ao longo do tempo. Elas são, pelo contrário, uma colcha de retalhos de soluções individuais para problemas dolorosos, um remendo de tantas soluções a ponto de tais retalhos nunca formarem um todo, tornandose um emaranhado de problemas no sistema de proteção à saúde. E como achamos engraçado ao vê-lo, porque não tem um único pedaço de tecido que tenha sido confeccionado concomitantemente, mas sim pedaços adjacentes uns aos outros, e que foram então costurados todos juntos em suas bordas.

\section{NACIONALIZAÇÃo DA PROTEÇÃo À SAÚDE}

Eu não estou usando a palavra "nacionalização" no sentido de assumir - comando de funções privadas da alçada do governo nacional, mas sim deixar claro que a população almeja cada vez mais uma proteção à saúde, de modo que tenha um valor amplo, de alta difusão, e que espera uma solução do governo. Nos Estados Unidos, nossa Constituição e sua referida Declaração de direitos reserva todos os poderes ao Governo estadual, a não ser que sejam especificamente designados ao Governo nacional. Apesar disso, muitas questões de saúde foram amparadas pelo Congresso $\mathrm{Na}$ cional, e transformadas em leis. Isso ocorreu porque muitos setores da população se aperceberam do fato de que tais questões consistentemente ultrapassavam os limites da alçada do Governo estadual. Eles observaram que comidas adulteradas e drogas com rótulos falsos pareciam cruzar as fronteiras entre os Estados, até mais facilmente que os produtos legalizados, e o consumidor queria proteção contra produtos ruins, não importando se eram feitos perto ou longe de casa. Na legislação americana atual, também são levados em consideração os aspectos referentes à preocupação das indústrias, e é interessante notar que freqüentemente há apoio das indústrias para as leis de proteção de âmbito nacional que insistem em sua uniformização para todo o País. Eu suspeito que isso se deva ao fato de que a indústria reconheceu a ineficácia de fazer 'receitas separadas', rótulos e propagandas para produtos destinados a Estados diferentes. Se há um padrão nacional para proteger o consumidor, há também um padrão nacional que o fabricante deva seguir. Eu creio ser justo observar que nossa estrutura e nosso sistema de transporte melhoraram, nossos fabricantes se tornaram economicamente interessados em mercados mais distantes. $E$ esse interesse fez com que não só meramente tolerassem a legislação, mas, ainda mais, que preferissem as leis a ter de estipular padröes diferentes para cada Estado. 


\section{ESTRUTURA DO FDA PARA PROTEÇÃo À SAÚDE}

\section{Por produto}

Em geral, pode-se dizer que o FDA contribui com a proteção à saúde fiscalizando produtos. Obviamente, quando se fiscaliza produtos a contento, deve-se, do mesmo modo, fiscalizar o fabricante, mas nosso estatuto está organizado de acordo com as linhas de produtos, em vez de estar delimitada por linhas de comportamento. Nossa "Lei fundamental" define os tipos de produtos que fiscalizamos: alimentos, remédios, medicamentos veterinários, compostos biológicos, aparelhos clínicos, aparelhos ligados à área de radiologia e cosméticos. Na maioria dos casos, nossas regras procuraram denominar os diferentes modos pelos quais um produto pode ser adulterado com algo prejudicial; ou possa ser meramente descategorizado por declarações falsas ou errôneas. Isso foi inadequado por dois motivos: primeiro, porque sempre estávamos atrás de um problema que tinha sua origem em nós mesmos; em segundo lugar, porque o Governo sempre tinha a árdua tarefa de desenvolver evidência cientifica para provar que o produto era prejudicial, ou que estava sendo comercializado de maneira incorreta.

Depois de uma série de tragédias ou desastres iniciais, a lei foi modificada para que a nós fosse designada a tarefa de pré-aprovar novos produtos antes que entrassem no mercado. O Congresso institui a lei de modo que uma empresa farmacêutica que estivesse procurando introduzir no mercado uma nova droga tivesse de usar seu próprio tempo e dinheiro para avaliar como obter um produto consistente, como medir o seu potencial, ser testado muito cuidadosamente quanto à sua toxicidade e também quanto a seus efeitos benéficos, e então submeter os resultados ao FDA. Esse sistema ajudou de diversas maneiras:

1 - A população não se submetia a um novo produto até que a empresa farmacêutica e o Governo estivessem de acordo quanto à segurança e eficácia do produto, e desse modo haveria menos desastres advindos de produtos porventura danosos.

2 - O dinheiro da população podia ser poupado, tendo o Governo como revisor e não como experimentador. Nosso sistema econômico permite a geração de altos lucros às indústrias que aceitam o risco econômico de desenvolver novas drogas, que são caras. Assim, as empresas têm condições econômicas de gastar grandes somas de dinheiro, necessárias para que testem e desenvolvam novas drogas; $e$ elas são recompensadas por direcionar seus recursos para medicamentos que a população poderá adquirir, ou seja, drogas para as quais exista grande necessidade de uso. E nós não precisamos gastar o dinheiro do contribuinte para desenvolver e testar novas drogas; já é bastante caro contratar os peritos necessários para avaliar o trabalho feito por outros.

3 - Se há comercialização de uma droga não aprovada, nossa luta contra ela não precisa ser uma enorme batalha que envolve peritos 
médicos, debatendo infinitamente se ela funciona ou não. A questão legal, ao contrário, é sobre se a droga ganha sua aprovação, seu direito de entrar no mercado. Em caso negativo, ela deve ser removida do mercado até que seja aprovada, e até que se prove que é segura e eficaz.

\section{Por Conduta}

Dentro do âmbito dos produtos fiscalizados, nossa atividade no ramo de alimentos, medicamentos e cosméticos especificamente fiscaliza a conduta ao referir como crimes certos atos referentes a essas categorias de produtos. É crime, obviamente, adulterar, adicionar qualquer substância nociva a um produto regulamentado e também é crime 'descategorizar' tal produto empregando alguma declaração inverídica em seu rótulo. Mas nossa Lei fundamental vai além e declara crime fabricar uma droga em condições que não asseguram o cumprimento dos atuais manuais de boas práticas de fabricação. Em outra linha de conduta semelhante, nosso decreto declara crime fabricar ou manter alimento em circunstâncias nas quais ele possa vir a ser contaminado por impurezas. Em ambos os casos, o próprio produto pode estar livre de qualquer contaminante verdadeiro. Mas, devido à importância desses elementos especiais (alimentos e drogas) em nossas vidas, nosso Congresso decretou que fabricá-los ou armazená-los em condições negligentes constitui crime. E nossa Corte Suprema sustentou tais requisitos constrangedores, notando que nas circunstâncias de comercialização do mundo moderno é melhor impor esse alto padrão de qualidade ao fabricante (ou responsável pelo armazenamento), que tem o controle das condiçōes de fabricação e armazenagem, que impor o risco de tais falhas ao consumidor, que é amplamente incapacitado para isoladamente mudar tais condições.

\section{Por uma diversidade de atos legais}

Mas nossa legislação reconhece que precisamos de uma série de respostas legais a produtos inadequadamente regulamentados, alguns dos quais possam ter-se tornado transgressores em circunstâncias em que não seria justo processar qualquer pessoa por seu erro, ou até em circunstâncias nas quais não se poderia dizer quem foi responsável pelo produto defeituoso. Então, nossa legislação possibilita uma série de repostas legais.

\section{Decisões na aprovação do produto}

Nós podemos nos recusar a aprovar um novo produto até que sua eficácia e segurança sejam provadas. Podemos anular a aprovação e remover do mercado um produto, como uma nova droga, se pudermos provar que ela não mais atende aos requisitos dos padrões de segurança e eficácia sob os quais foi aprovada, que novos dados demonstram que ela nāo se mostra 
eficaz ou segura, ou que uma nova análise dos antigos dados, considerando-se padrões científicos atuais, revele que ela não mais se mostra segura e eficaz. Podemos tomar tais atitudes de aprovação em nossas própria Agência, sem nos referirmos ao Departamento de Justiça, ou aos tribunais, embora tenhamos de provar nossas alegações em uma audiência administrativa, conduzida em nossa Agência por um Representante Jurídico-Administrativo. E nossos adversários podem apelar da decisão administrativa para a Justiça comum se vencermos na etapa da audiência administrativa.

\section{Apreensão judicial de produtos transgressores}

Em uma medida de apreensão, podemos agir por intermédio do nosso Departamento de Justiça para que o produto ilegal seja removido e confiscado pelo Governo e destruído se a Corte de Justiça entender que ele viola a lei. Esse procedimento foi copiado da antiga "Lei Marítima e dos Almirantes (Admiralty and Maritime Law), quando navios tinham de ser retidos rapidamente, antes que se afastassem, e algumas vezes antes que se pudesse determinar quem os possuía. E assim também com uma carga de manteiga rançosa transportada em caminhões, ou aparelhos de raios- $X$ não aprovados, ou drogas com rótulos falsificados. Em tais instâncias, o nome do caso pode ser "Estados Unidos contra 22.451 libras de um produto alimentício, Manteiga", sem ter de denominar o dono, porque nesse caso não nos importa quem o possui. Nos importamos apenas com o fato de que esteja rançoso, ou estragado, ou seja 'adulterado', segundo nossa Lei, assim merecendo condenação e destruição. Se alguém desejar reivindicar a manteiga e defender sua qualidade, passa então a fazer parte do caso como 'requerente', e cada um de nós tenta convencer o Juiz de que nossa posição é correta. Se ninguém vem a reivindicar o artigo confiscado, nós pedimos ao Juiz para que o decrete adulterado, e que ordene sua destruição.

A grande maioria de nossos casos de apreensão de produtos é conduzida sem julgamento judicial, por meio de um documento de ajuste chamado "Decreto de Consentimento" (Consent Decree), no qual o requerente dos bens admite que eles estão adulterados ou então que transgridem de alguma maneira a legislação, como consta. da acusação governamental, e então a Corte de Justiça decreta que os bens transgressores, e os condena segundo o estatuto, mas permite que o requerente tente adequar o produto à legislação vigente. Algumas vezes, isso pode ser feito por meio de uma nova colocação de rótulo em um produto para corrigir um erro anterior, e algumas vezes isso pode ser feito através da seleção de um lote de latas apropriadas e não apropriadas para o consumo, e então destruir todas as que estejam amassadas ou vazando, e salvar as que estejam boas (depois de inspeção e confirmação governamental), e vendê-las sob supervisão governamental. 


\section{Injunções Judiciais}

Em uma medida judicial de injunção, nós pedimos à Corte que ordene a uma empresa ou seus responsáveis oficiais que parem de violar a "Lei de alimentos e drogas" (Food and Drug Law), e tomem medidas necessárias para corrigir condições ruins, e evitar futuras transgressões. Em casos de injunção, a empresa e os responsáveis oficiais são revelados, porque realmente nos importamos em saber quem é responsável pelas condições que nos levam a impetrar uma ordem judicial. Segundo nossa lei, a Corte move um processo para determinar se deve emitir a ordem judicial conforme requerida pelo Governo, e nesse processo, o Governo tem a obrigação de provar que aquele produto em particular está coberto por nossa legislação, que as condições da empresa violam a nossa lei em quaisquer dos aspectos descritos no estatuto, que esforços anteriores para que a empresa passe a cumprir a lei não foram bem sucedidos, e que uma ordem judicial é necessária para obrigá-la ao cumprimento da lei.

Uma vez que os julgamentos de tais atos podem ser amplamente contestados e demorar muito tempo, às vezes mais que um ano, a lei americana permite uma Injunção Preliminar, a ser instituída por um tribunal, para deter o status de um produto ou de uma empresa até que o julgamento possa ser agendado e finalizado. Os tribunais federais estão habilitados para dar entrada em tais ordens judiciais após uma breve audiência, sem a necessidade de um julgamento completo. Em situações realmente emergenciais, nossos tribunais podem ir além e entrar com uma Ordem de Restrição Temporária (TRO), sem mesmo haver uma audiência, caso a situação seja muito danosa, ou potencialmente prejudicial à população, e que não haja tempo suficiente para que os advogados da empresa agendem uma audiência com os tribunais de justiça. O tribunal pode permitir a ambas as partes que façam uma audiência por telefone, ou pode entrar com uma TRO sem uma audiência, baseado unicamente nas representações e nos documentos da parte requerente da ordem judicial. Nesse caso, as TROs são de duração muito limitada, apenas 10 dias, com uma possível prorrogação de mais 10 dias, porque prevê tempo suficiente para que o tribunal ouça as argumentações de ambas as partes em uma Injunção Preliminar.

A maioria de nossos casos de injunção são também resolvidos sem um julgamento completo, novamente por um Decreto de Consentimento, e freqüentemente com alguma provisão que faça com que a firma acionada melhore suas operações, contrate um consultor especializado às suas próprias custas, e continue com suas atividades apenas após inspeção do consultor e da FDA, de modo que os mesmos atestem que a empresa esteja pronta para reiniciar suas atividades no mercado. Em tais instâncias, solicitamos que a firma acionada pague à União as despesas com inspeções extras, necessárias devido à medida de Injunção. Desse modo, a empresa fica diretamente responsável pelos custos de inspeções e supervisões extras, isentando o contribuinte de tais custos, inclusive os outros membros dessa empresa que estavam seguindo a legislação a contento. É importante notar 
que tais despesas são recolhidas pelo Tesouro Nacional, e não por nossa Agência.

\section{Execução Criminal}

Por fim, nossa lei nos autoriza a pedir ao Departamento de Justiça que entre com um processo criminal contra entidades que violem a lei. Temos como política limitar sanções tão severas aos réus que não responderam a medidas de impacto menor, mas fazemos exceções a atitudes muito nocivas, mesmo quando não há um longo histórico de violação de conduta. Nossa Corte Suprema demonstrou grande apoio ao uso de nossas instâncias criminais, mesmo quando o funcionário responsável da empresa pode declarar que ele não estava pessoalmente envolvido no processo de contaminação do alimento e não pretendia a sua possível contaminação. A Corte sustentou uma condenação criminal de delito do funcionário mesmo que ele exerça uma supervisão remota do setor de armazenamento que estava impróprio, uma vez que ele tinha a capacidade e a obrigação de assegurar que o alimento vendido à população fosse mantido em condições de higiene, e porque ele falhou no exercicio de sua responsabilidade, evitando a existência de tais condições de limpeza no setor de armazenamento de. sua empresa.

Para os crimes de extrema relevância, com penalidades mais altas, temos de provar os elementos tradicionais de dolo, assim como o fato da violação da lei, com o propósito de sustentar uma condenação criminal. Embora as instâncias criminais sejam nossas sanções mais severas, elas ficaram mais numerosas nos últimos anos, uma vez que a Agência vem se beneficiando de um grupo especializado de investigadores criminais que está voltado a atividades criminais suspeitas com métodos investigativos modernos e tradicionais.

ANEXO 1

Panorama dos órgãos do FDA envolvidos nesse processo

Organizações privadas e comerciais

Entidades Assistenciais

Instituições Educacionais

Governo:

Local

Estadual

Federal

Judiciário 


\section{Legislativo}

Executivo

Departamento de Saúde e Serviços (DHHS)

Institutos Nacionais de Saúde (NIH)

Centros para Controles de Doenças (PHS)

Controle de Alimentos e Medicamentos (FDA)

Escritório do Delegado representante

*Escritório do Conselho Diretor

Centro para Segurança dos Alimentos e Nutrição

Centro para Regulamentaçāo de Medicamentos e Pesquisa

Centro para Medicina Veterinária

Centro para Aparelhos Clínicos e Saúde Radiológica

Órgão Administrativo de Financiamento de Tratamentos de Saúde (HCFA)

Departamento de Agricultura (USDA)

Departamento de Administração de Proteção Ambiental (EPA) 